\title{
An Investigation of the Relationship Between Fathers and Their Children at Preschool Level*
}

\author{
Özgün UYANIK ${ }^{* *}$ \\ Gözde İNAL KIZILTEPE ${ }^{* * * * *}$
}

\author{
Ümit Ünsal KAYA ${ }^{* * *}$ \\ Münevver CAN YAŞAR ${ }^{* * * * *}$
}

Received: 22 June 2015

Accepted: 27 November 2015

\begin{abstract}
This study aimed to investigate the relationship between fathers and their children at preschool level from low socioeconomic status according to some variables. The population of the study included the fathers of preschoolers attending to child care centers in Afyonkarahisar, all of which were affiliated to Ministry of National Education. However, 245 fathers whose children were attending to one of the child care centers in Afyonkarahisar during the 2012-2013 academic year, were included in the study group. As a data collection instrument, "Children Parent Relationship Scale" was used. While analyzing the data, as a result of Kolmogorov-Smirnov (K-S) normality test, Mann Whitney U Test for comparing two groups and Kruskal Wallis H Test for the comparison of more than two groups were used. The findings showed that the child's gender and number of children in the family affected father-child relationship whereas birth order and father's level of education did not.
\end{abstract}

Keywords: Early childhood education, father child relationship, low socioeconomic status

\section{Extended Abstract}

Purpose and Significance: Today, socioeconomic and cultural factors have been changed due to the widespread nuclear family type and thereby the altered roles and responsibilities among the parents. Fathers have started to take a more active and indispensable role in the upbringing and education of the child (Tezel Şahin, 2003; Kuzucu, 2011). The relationship between the child and the father starts at infancy and at preschool level this relationship moves on with many activities such as miming, humorous and physical games, role-modeling, chatting about the outer social world, etc. all of which enhance the quality of the relationship (Bee \& Boyd, 2009; Berk, 2013). Studies have shown that a strong interaction between the child and the father has positive effects on self-concept, the child's prosocial behaviors and peer relationships (Marsiglio, Amato, Day, \& Lamb, 2000; Thomas, Krampe, \& Newton, 2008). The relationship between the child and the father can be affected by many factors such as number of children in the family, child's gender and personal characteristics,

\footnotetext{
* This study was presented as an oral presentation at the "Second International Congress on Research in Education Innovative Research in Education: Implications for Future", İzmir, 25-27 April, 2014.

${ }^{* *}$ Corresponding author: Assist. Prof. Dr., Afyon Kocatepe University, Afyonkarahisar, Turkey, ozgunuyanik@hotmail.com

${ }^{* * * *}$ Lecturer, Afyon Kocatepe University, Afyonkarahisar, Turkey, ukaya03@gmail.com

***** Assist. Prof. Dr., Adnan Menderes University, Aydın, Turkey, ggozdeinal@ gmail.com

${ }^{* * * * *}$ Assoc. Prof. Dr., Afyon Kocatepe University, Afyonkarahisar, Turkey, munevver2002@yahoo.com
}

\section{Citation Information}

Uyanık, Ö., Kaya, Ü. Ü., İnal-Kızıltepe, G., \& Can-Yaşar, M. (2016). Çocuğu okul öncesi eğitim kurumuna devam eden babalarin çocuklari ile olan ilişkilerinin incelenmesi. Kuramsal Eğitimbilim Dergisi [Journal of Theoretical Educational Science], 9(4), 515-531. 
socioeconomic status and cultural heritage of the family (Tezel Şahin \& Özyürek, 2008; Bee \& Boyd, 2009; Sezer, 2010). In the light of these findings, in this study it was aimed to investigate the relationship between the fathers and their children at preschool level from low socioeconomic status according to some demographical variables which are as follows: child's gender, birth order, number of children in the family, father's educational level.

Method: The population of the study included the fathers of preschoolers attending to child care centers in Afyonkarahisar all of which were affiliated to Ministry of National Education. Criterion sampling method which is one of the purposive sampling method was used in the study. The criteria were that the fathers were 25-30 years old and from low socioeconomic status families which were determined by the provincial directorate of national education. According to these basic criteria, 245 fathers whose children were attending to one of the preschool centers in Afyonkarahisar - Turkey during 2012-2013 academic year were included in the study group. The participation was voluntary and necessary consent form for the participation of children were obtained from the parents. According to the demographical findings, it was found out that $48 \%$ of the children were female, $51.4 \%$ were male; $51.8 \%$ were the only child, $23.3 \%$ middle child, $24.9 \%$ were the last child. Of the fathers, $50.2 \%$ were graduates of elementary schools whereas $34.3 \%$ were high school and $15.5 \%$ had bachelor's degree. According to the profession of fathers, $50.6 \%$ were workers, $18.4 \%$ were civil servants, and $31 \%$ were selfemployed.

To collect data, general information form which was developed by the researchers and inquiring gender, number of siblings, parents' educational level and profession together with Child Parent Relationship Scale-CPRS were used. The original draft of Child Parent Relationship Scale-CPRS was initially developed by Pianta (1992) in order to investigate mother-child relationship. This scale, then, was adapted to Turkish by Akgün and Yeşilyaprak (2010) after validity and reliability analysis for 4-6 year old children. The Turkish version consists of 24 items with 5 point Likert scale from (1) Definitely inappropriate to (5) Definitely appropriate. In the scale, there are items implying both positive and negative attitudes which were reversed while scoring. High scores refer to a negative relationship whereas low scores from the scale refer to positive relationship. The maximum score is 120 while the minimum score that can be obtained is 24 .

Since only mothers were included in the sample of Akgün and Yeşilyaprak's (2010) adaptation study and the sample of this study was intended to include fathers, internal consistency coefficients (Cronbach alpha) were re-calculated. After the analysis carried out, internal consistency coefficients were found as .71 for conflict dimension, .78 for positive relationship dimension and .78 total.

In order to determine whether the fathers' scores from Child Parent Relationship ScaleCPRS showed normal distribution, Kolmogorov-Smirnov (K-S) normality test was used. According to results, Mann Whitney U test was used for two group comparison 
with no normal distribution and Kruskal Wallis $\mathrm{H}$ test with Bonferoni correction was preferred for more than two groups with variables showing no normal distribution. The significance level was set as .05 which meant that $\mathrm{p}<.05$ showed a significant difference.

Results: There was no statistically significant difference between the fathers' scores from the conflict dimension subtest $(\mathrm{U}=7213.5, \mathrm{p}>.05)$ of Child Parent Relationship Scale-CPRS and their total score ( $U=6869.5, p>.05)$ according to children's gender whereas a significant difference was found out for positive relationship sub-test $(\mathrm{U}=6359.5, \mathrm{p}<.05)$. Again, no statistically significant difference was found among the father's scores from conflict dimension subtest $\left(X^{2}=0.491, p>.05\right)$ of Child Parent Relationship Scale-CPRS, positive relationship dimension sub-test $\left(X^{2}=1.51, p>.05\right)$ and their total scores $\left(\mathrm{X}^{2}=0.521, \mathrm{p}>.05\right)$ according to the children's birth order. Among the fathers' scores from conflict dimension subtest $\left(\mathrm{X}^{2}=7.6, \mathrm{p}<.05\right)$ of Child Parent Relationship Scale-CPRS according to number of siblings was significant; however, between the scores from positive relationship dimension sub-test $\left(X^{2}=0.237, p>.05\right)$ and their total scores $\left(\mathrm{X}^{2}=5, \mathrm{p}>.05\right)$ was not significant. Again, there was no significant difference among the fathers' scores from conflict dimension subtest $\left(X^{2}=2.69, p>.05\right)$ of Child Parent Relationship Scale-CPRS according to the fathers' educational level, the scores from positive relationship dimension sub-test $\left(X^{2}=0.015, \mathrm{p}>.05\right)$ and their total scores $\left(\mathrm{X}^{2}=2.1, \mathrm{p}>.05\right)$.

Discussion and Conclusion: There are studies in the literature supporting the findings of this study. Ünüvar (2008) suggested that fathers having daughters were found out to spend more quality time compared to the fathers of sons. Driscoll and Pianta (2011), similarly, reported that fathers have more intimate relationship with their daughters compared to their sons. In a study, which investigated the birth order variable, it was found out that parental attitude of parents having 5-6-year-old children is independent of the child's birth order (Tezel Şahin \& Özyürek, 2008). On the other hand, Poyraz (2007) put forward that sense of paternity became negatively affected as the number of children increased while Seçer, Çeliköz and Yaşa (2007) reported that fathers' interest scores towards paternity especially after the second child. Veenhoven and Verkuyten (1989) suggested that the single child felt lonely and disadvantaged in terms of opportunities for the development of social skills since single child families were more interfering and protective towards their child (as cited in Avşar, 2013). The results of the aforementioned study are parallel with the findings of this study. 


\title{
Çocuğu Okul Öncesi Eğitim Kurumuna Devam Eden Babaların Çocukları ile Olan İlişkilerinin İncelenmesi ${ }^{*}$
}

\author{
Özgün UYANIK** \\ Gözde İnal KIZILTEPE**** \\ Ümit Ünsal KAYA**** \\ Münevver Can YAȘAR ${ }^{* * * * * *}$
}

Makale Gönderme Tarihi: 22 Haziran 2015

Makale Kabul Tarihi: 27 Kasım 2015

ÖZ: Araştırma, çocuğu okul öncesi eğitim kurumuna devam eden alt sosyoekonomik düzeydeki babaların çocukları ile olan ilişkisinin bazı değişkenlere göre incelenmesi amacıyla yapılmıştır. Araştırmanın çalışma evrenini, Afyonkarahisar il merkezinde İl Milli Eğitim Müdürlüğ̈̈'ne bağlı okul öncesi eğitim kurumlarına devam eden çocukların babaları oluşturmaktadır. Araştırmanın çalışma grubuna, çocuğu 2012-2013 eğitim öğretim yılında İl Milli Eğitim Müdürlüğ̈̈’ne bağlı okul öncesi eğitim kurumlarına devam eden 245 baba dahil edilmiştir. Araştırmada veri toplama aracı olarak, çocuklar ve aileleri ile ilgili bilgi almak amacıyla Genel Bilgi Formu ve babaların çocukları ile ilişki düzeylerini belirlemek amacıyla Pianta (1992) tarafindan geliştirilen ve Akgün ve Yeşilyaprak (2010) tarafindan uyarlanan "Çocuk Anababa İlişki Ölçeği" kullanılmıştır. Elde edilen verilerin analizinde KolmogorovSmirnov (K-S) normallik testi sonucunda, gruplar arası farklılık incelenirken ikili gruplarda Mann Whitney U Testi, ikiden fazla gruplarda ise Bonferroni düzeltmeli Kruskal Wallis H Testi kullanılmıştır. Araştırmanın sonucunda; çocuğun cinsiyeti ile ailedeki çocuk sayısı değişkenleri baba çocuk ilişkisini etkilediği, doğum sırası ile babanın öğrenim durumu değişkenlerinin ise etkili olmadığı bulunmuştur.

Anahtar kelimeler: Okul öncesi eğitim, baba çocuk ilişkisi, alt sosyoekonomik düzey

\section{Giriş}

Çocukların yakın çevresini oluşturan ebeveynlerin, fizyolojik, ekonomik ve sosyal yönden çocuğa etkisi olduğu, ebeveynlerin beklentilerinin, çocuk yetiştirme tutumlarının ve çocukla iletişimlerinin de çocukların gelişiminde büyük önemi olduğu bilinmektedir. Bebekler, dünyaya geldikleri andan itibaren rahatlatılma, korunma ve yatı̧sırırılma gereksinimlerine duyarlılık gösteren ve araştırmada bulunmalarını destekleyen ebeveyne karşı güçlü duygusal bağlar kurma eğilimindedir (Bee \& Boyd, 2009; Berk, 2013). Ebeveyn ile bebek arasında doğumla başlayan bu ilişki, yakınlığın devam etmesini sağlayan iç içe geçmiş içgüdüsel davranışlar örüntüsüne ve ebeveyn ile bebeğin birbirleriyle uyumlu olmasina bağlı olarak gelişim göstermektedir (Bee \& Boyd, 2009).

Alan yazında çoğunlukla anne ile bebek arasındaki ilişki üzerinde durulmuş olunsa da günümüzde artık bu durum sosyoekonomik ve kültürel etkenler, çekirdek aile yapısının yaygınlaşması ve bireylere düşen görev ile sorumlulukların değişmesi nedeniyle farklılaşmıştır. Çocuğun gelişimi ve eğitiminde aktif bir rol almaya başlayan "baba" bu ilişkinin vazgeçilmez bir parçası haline gelmiştir (Tezel Şahin, 2003; Kuzucu, 2011). Babanın bebeğe karşı duyarlı bakımı, onunla konuşması, oyunlar oynaması ve iletişimi bebek ile baba arasında başarılı bir ilişsinin kurulmasını

\footnotetext{
* $\mathrm{Bu}$ araştırma "Second International Congress on Research in Education Innovative Research in Education: Implications for Future, İzmir, 25-27 April, 2014" kongresinde sözlü bildiri olarak sunulmuştur.

${ }^{* *}$ Corresponding author: Yrd. Doç. Dr., Afyon Kocatepe Universitesi, Afyonkarahisar, Türkiye, ozgunuyanik@hotmail.com

****okutman, Afyon Kocatepe Üniversitesi, Afyonkarahisar, Turkiye, ukaya03@gmail.com

***** Yrd. Doç. Dr. Adnan Menderes Üniversitesi, Aydın, Turkiye, ggozdeinal@ gmail.com

***** Doç. Dr. Afyon Kocatepe Üniversitesi, Afyonkarahisar, Turkiye, munevver2002@ yahoo.com
} 
sağlamaktadır (Amato, 1994; Berk, 2013). Bebeğin bakımı ile başlayan baba ve bebek arasındaki ilişki, okul öncesi dönem süresince babaların çocuklarılla birlikte çeşitli taklit, mizahi ve fiziksel oyunlar oynaması, olumlu davranış becerilerini taklit etmesi, sosyal dünya hakkında öğrendikleri ile ilgili sohbet etmesi gibi etkinliklerle devam etmekte ve bu etkinlikler baba ile çocuk arasında sağlıklı bir ilişkinin gelişmesini desteklemektedir (Bee \& Boyd, 2009; Berk, 2013).

Babaların çocukları ile birlikte etkili zaman geçirerek çocuklarını bağımsız davranmaya teşvik etmesi, sosyal etkileşime sokması ve çocuklarına zengin uyarıcılar sunması çocukların bilişsel, dil, sosyal ve duygusal alandaki gelişimini desteklemektedir. Araştırmalar, baba ile çocuk arasındaki doğru etkileşimin çocukların akademik başarısını, olumlu benlik algısını, prososyal davranışlar geliştirmesini ve sağlıklı akran ilişkileri kurmasını olumlu yönde etkilediğini ortaya koymaktadır (Marsiglio, Amato, Day \& Lamb, 2000; Thomas, Krampe \& Newton, 2008). Okul öncesi dönemde baba ile çocuk arasındaki olumlu ve güvenli ilişkinin; Browne \& Rife (1991) çocuğun okulda daha az problem davranış göstermesine; Grossman ve diğerleri (2002) çocuğun uzun vadede güvenli ilişkiler kurmasına; Paquette ve diğerleri (2003) çocukların akranlarına karşı fiziksel olarak gösterdiği agresif davranışların azalmasına; Koç (2000), Barber \& Erickson (2001) ergenlik döneminde çocukların sosyal girişkenliğine ve sosyal alandaki becerilerine olumlu yönde etkisi olduğunu tespit etmişlerdir. Ayrıca yine okul öncesi dönemde baba ile çocuk arasındaki sıcak ve güvenli ilişkinin; Lamb (2010) çocuğun duygusal ve bilişsel gelişimine, Pianta (1997-1999), Taris ve Bok (1996) akademik başarısına ve Wood (2007) öğrenmeye karşı daha istekli olmasına etkisi olduğunu belirlemişlerdir.

Baba ve çocuk arasındaki "belirli bir geçmişe ve hafızaya sahip olan; gözlenebilir davranışlardan çok bireylerin birbirleri ile etkileşimi, beklentileri, inançları, düşünceleri ve birbirlerini etkileme düzeyleri” olarak tanımlanan "ilişki” (Pianta, 1997) ailedeki çocuk sayısı, çocuğun cinsiyeti, ailenin sosyoekonomik durumu ve kültürel özellikler gibi pek çok durumdan etkilenmektedir (Tezel Şahin ve Özyürek, 2008; Bee \& Boyd, 2009; Sezer, 2010). Bu durum, baba ve çocuk arasındaki ilişkiyi etkileyen etkenlere yönelik araştırmalar yapılmasını gerektirmektedir. Alan yazındaki baba-çocuk ilişskisi, babanın çocuğun eğitimine katılımının, babaların babalık rolü algısının demografik değişkenler açısından incelendiği çalışmalara bakıldığında, demografik değişkenler açısından farklı bulgular elde edildiği görülmektedir. Örnek olarak; cinsiyet ve çocuk sayısı değişkenleri açısından incelendiğinde, bazı çalışmalarda çocuğun cinsiyetinin baba-çocuk ilişkisini, baba katılımını, babalık algısını etkilediğine ilişkin bulgular (Harris \& Morgan, 1991; McBride, Schoppe \& Rane, 2002; Ünüvar, 2008); bazı araştırmalarda ise etkilemediğine ilişkin bulgular mevcuttur (Coley \& Morris 2002; Poyraz, 2007; Paulson, Dauber \& Leiferman, 2010; Sımsık1 ve Şendil, 2014). Aynı şekilde ailedeki çocuk sayısının fazla olmasının, baba çocuk ilişkisini, baba katılımını, babalık algısını olumsuz yönde etkilediğine ilişkin bulgular (Paquette, Bolte, Turcotte, Dubeau \& Bouchard, 2000; Özyürek ve Tezel Şahin, 2005; Seçer, Çeliköz ve Yaşa, 2007) mevcutken, çocuk sayısının fazla olmasının baba çocuk ilişkisini, baba katılımını, 
babalık algısını olumlu yönde etkilediğine ilişkin bulgular da vardır (Ishii-Kuntz, Makino, Kato \& Tsuchiya, 2004; Hamamc1, 2005). Bu noktadan hareketle araştırmada, çocuğu okul öncesi eğitim kurumuna devam eden alt sosyoekonomik düzeydeki babaların çocukları ile olan ilişkisinin bazı demografik değişkenlere (çocukların cinsiyeti, doğum sırası, evdeki çocuk sayısı, babanın öğrenim durumu) göre incelenmesi amaçlanmıştır.

\section{Yöntem}

\section{Evren ve Örneklem}

Araştırmanın çalışma evrenini, Afyonkarahisar il merkezinde Milli Eğitim Müdürlüğü'ne bağlı okul öncesi eğitim kurumlarına devam eden çocukların babaları oluşturmaktadır. Araştırmada amaçlı örnekleme yöntemlerinden ölçüt örnekleme kullanılmıştır. Amaçlı örnekleme, zengin bilgiye sahip olduğu düşünülen durumların derinlemesine çalışılmasına olanak vermektedir. Araştırmacı seçilen durumlar bağlamında doğa ve toplum olaylarını ya da olgularını anlamaya ve bunlar arasındaki ilişkileri keşfedip açıklamaya çalışır. Ölçüt örnekleme kullanılan araştırmalarda da gözlem birimleri belirli niteliklere sahip kişiler, olaylar ya da durumlardan oluşabilir. $\mathrm{Bu}$ durumda örneklem için belirlenen ölçütü (temel nitelikleri) karşılayan birimler örnekleme alınırlar (Büyüköztürk, Kılıç, Akgün, Kardeniz ve Demirel, 2009).

$\mathrm{Bu}$ araştırmaya katılacak babaların seçiminde, çocuğu alt sosyoekonomik düzeydeki okullara bağlı (İl Milli Eğitim Müdürlüğü'nün belirlediği liste doğrultusunda) okul öncesi eğitim kurumlarına devam eden ve 25-30 yaş aralığındaki babalar olması temel ölçüt olarak belirlenmiştir. Bu temel ölçütler uyarınca, 2012-2013 eğitim öğretim yılında Afyonkarahisar il merkezinde İl Milli Eğitim Müdürlüğü'ne bağlı ilkokullar arasından ölçüt örnekleme yöntemiyle seçilen toplam on okuldaki anasınıflarına devam eden 245 çocuğun babası araştırmaya dahil edilmiştir. Babaların görüşüne gönüllülük esasına göre başvurulmuştur.

Araştırmaya dahil edilen babaların çocuklarının, \%48.6'sının kız, \%51.4'nün erkek; \%51.8'nin tek çocuk, \%23.3'nün ortanca çocuk, \%24.9'nun son çocuk olduğu belirlenmiştir. Araştırmaya dahil edilen babaların \%50.2'sinin ilköğretim, \%34.3'nün lise, \%15.5'nin üniversite mezunu olduğu; \%18.4'nün memur, \%50.6'sının işçi, \%31.0'nin serbest meslek sahibi olduğu tespit edilmiştir.

\section{Veri Toplama Araçları}

Genel Bilgi Formu: Araştırmacılar tarafindan geliştirilen formda, okul öncesi eğitim kurumuna devam eden çocuğun cinsiyeti ve kaçıncı çocuk olduğu, ailedeki çocuk sayısı, babanın öğrenim durumu ve mesleği ile ilgili sorular yer almaktadır.

\section{Çocuk Anababa İlişki Ölçeği-ÇAİÖ (Child Parent Relationship Scale-CPRS):}

Ölçeğin orijinali Pianta (1992) tarafından anne-çocuk ilişkisini anlamak ve değerlendirmek amacıyla oluşturulmuştur. Ölçeğin maddeleri hazırlanırken anne çocuk etkileşimi literatüründen, bağlanma teorisinden ve Bağlanma Q-Set (Waters \& Dean, 1985) ölçeğinden yararlanılmıştır (Akt: Akgün ve Yeşilyaprak, 2010). Ölçek, Akgün ve 
Yeşilyaprak (2010) tarafından geçerlik güvenirlik çalışması yapılarak Türkçe'ye uyarlanmıştır. Türkçe'ye uyarlanırken ölçek, 4-6 yaş grubu çocuğu olan 234 anneye uygulanmış ve elde edilen veriler doğrultusunda analizler yapılmıştır. Türkçe formu 24 maddeden oluşan ölçek, 5'li likert tipi bir ölçek olup (1) Kesinlikle uygun değil ile (5) Kesinlikle çok uygun arasında yanıtlanır. Ölçekte olumlu ve olumsuz ifadeler bulunmakta ve olumlu ifadeler tersine çevrilerek puanlanmaktadır. Ölçekten yüksek puan alma olumsuz ilişkiyi, düşük puan alma olumlu ilişkiyi göstermektedir. Toplam puan en yüksek 120 ve en düşük 24 arasındadır.

Ölçeğin Türkçeye uyarlanan versiyonunda faktör analizi sonuçlarına göre çatışma boyutu ve olumlu ilişki boyutu olmak üzere ölçek iki faktörlü olarak belirlenmiştir. Çatışma boyutu alt ölçeğinde yer alan maddelerin faktör yük değeri .38 ile .72 arasında, olumlu ilişki boyutu alt ölçeğinde ise .42-.72 arasında değişmektedir. Ölçeğin test tekrar test güvenirlik katsayısı çatışma boyutu alt ölçeği için .98 (p<.01); olumlu ilişki boyutu alt ölçeği için .96 $(\mathrm{p}<.01)$; toplam puan için .96 $(\mathrm{p}<.01)$ bulunmuştur. Ölçeğin iç tutarlık katsayıları (Cronbach alfa) çatışma boyutu alt ölçeği için .85; olumlu ilişki boyutu alt ölçeği için .73 ve toplam puan için .73 olarak belirlenmiştir. Spearman Brown düzeltmesinden sonra testin iki yarısı arası korelasyonu ise aynı sırayla .84, .73 ve .72 olarak saptanmıştır (Akgün ve Yeşilyaprak, 2010).

Akgün ve Yeşilyaprak (2010) tarafindan ölçeğin Türkçe’ye uyarlama çalışmasında örnekleme grubuna sadece anneler dahil edildiğinden ve bu araştırma, çocuğu okul öncesi eğitim kurumuna devam eden babaların çocukları ile olan ilişkisinin incelenmesi amacıyla yapıldığından ölçeğin iç tutarlık katsayıları (Cronbach alfa) yeniden incelenmiştir. $\mathrm{Bu}$ değerlendirme sonucunda ölçeğin iç tutarlılık katsayıları çatışma boyutu alt ölçeği için .71, olumlu ilişki boyutu alt ölçeği için .78 ve toplam puan için .75 olarak belirlenmiştir.

\section{Verilerin Analizi}

Babaların Çocuk Anababa İlişki Ölçeği'nden aldıkları puanların normal dağılım gösterip göstermediği Kolmogorov-Smirnov (K-S) normallik testi ile analiz edilmiştir. Kolmogorov-Smirnov (K-S) normallik testi sonucunda, gruplar aras1 farklıl1k incelenirken ikili gruplarda normal dağılmayan değişkenlerde Mann Whitney U Testi, ikiden fazla gruplarda ise normal dağılmayan değişkenlerde Bonferroni düzeltmeli Kruskal Wallis H Testi kullanılmıştır. Gruplar arası farklılık incelenirken; anlamlılık seviyesi olarak .05 kullanılmış olup, $\mathrm{p}<.05$ olması durumunda gruplar arasında anlamlı farklılı̆̆ın olduğu, $\mathrm{p}>.05$ olması durumunda ise anlamlı farklılığın olmadiğ 1 belirtilmiştir (Büyüköztürk ve diğerleri, 2009).

\section{Bulgular}

Çocuğu okul öncesi eğitim kurumuna devam eden alt sosyoekonomik düzeydeki babaların çocukları ile olan ilişkisinin bazı değişkenlere (çocukların cinsiyeti, doğum sırası, ailedeki çocuk sayısı, babanın öğrenim durumu) göre incelenmesi amaciyla yapılan araştırmada elde edilen bulgular aşağıda tablolar halinde sunulmuş ve tartışılmıştır. 
Tablo 1

Babaların Çocuklarının Cinsiyetlerine Göre Çocuk-Anababa İlişki Ölçeği Puanlarına Iliş̧kin Mann-Whitney U Testi Sonuçları

\begin{tabular}{|c|c|c|c|c|c|c|}
\hline \multirow[b]{2}{*}{ ÇAIÖ } & \multirow[b]{2}{*}{ Cinsiyet } & \multirow[b]{2}{*}{$n$} & \multirow[b]{2}{*}{$X$} & \multirow[b]{2}{*}{ Sira Ort. } & \multicolumn{2}{|c|}{ Mann-Whitney U Test } \\
\hline & & & & & $U$ & $p$ \\
\hline \multirow{2}{*}{ Çatışma Boyutu } & $\mathrm{K} 1 \mathrm{z}$ & 119 & 32.0 & 120.6 & \multirow{2}{*}{7213.5} & \multirow{2}{*}{.609} \\
\hline & Erkek & 126 & 31.9 & 125.3 & & \\
\hline \multirow{2}{*}{ Olumlu İlişki Boyutu } & Kiz & 119 & 15.4 & 113.4 & \multirow{2}{*}{6359.5} & \multirow{2}{*}{$.039^{*}$} \\
\hline & Erkek & 126 & 16.5 & 132.0 & & \\
\hline \multirow{2}{*}{ Toplam Puan } & Kiz & 119 & 47.5 & 117.7 & \multirow{2}{*}{6869.5} & \multirow{2}{*}{.257} \\
\hline & Erkek & 126 & 48.4 & 128.0 & & \\
\hline
\end{tabular}

$*_{p}<.05$

Tablo 1 incelendiğinde, babaların çocuklarının cinsiyetine göre Çocuk-Anababa İlişki Ölçeği'nin Çatışma Boyutu Alt Ölçeği ( $U=7213.5$, p>.05) puanları ve toplam puanları $(\mathrm{U}=6869.5, \mathrm{p}>.05)$ arasında istatistiksel olarak anlamlı derecede farklılık görülmezken, Olumlu İlişki Boyutu Alt Ölçeği $(U=6359.5, p<.05)$ puanları arasında istatistiksel olarak anlamlı derecede farklılık görülmektedir. Bu sonuca göre, babaların kız ve erkek çocukları ile benzer çatışmalar yaşadığı, ancak babaların kız çocukları ile ilişkisinin erkek çocuklara göre daha olumlu olduğu söylenebilir.

Tablo 2

Babaların Çocuklarının Doğum Sırasına Göre Çocuk-Anababa İlişki Ölçeği Puanlarına İlişkin Kruskall-Wallis H Testi Sonuçları

\begin{tabular}{|c|c|c|c|c|c|c|c|}
\hline \multirow[b]{2}{*}{ ÇAÏÖ } & \multirow[b]{2}{*}{ Doğum Strası } & \multicolumn{6}{|c|}{ Kruskal Wallis H Testi } \\
\hline & & $n$ & $S d$ & $\bar{x}$ & Sira Ort. & $X^{2}$ & $p$ \\
\hline \multirow{3}{*}{ Çatışma Boyutu } & İlk Çocuk & 127 & 2 & 31.2 & 119.9 & \multirow{3}{*}{0.491} & \multirow{3}{*}{.782} \\
\hline & Ortanca & 57 & 2 & 33.2 & 126.1 & & \\
\hline & Son Çocuk & 61 & 2 & 32.3 & 126.4 & & \\
\hline \multirow{3}{*}{$\begin{array}{l}\text { Olumlu İlişki } \\
\text { Boyutu }\end{array}$} & İlk Çocuk & 127 & 2 & 16.1 & 126.5 & \multirow{3}{*}{1.51} & \multirow{3}{*}{.469} \\
\hline & Ortanca & 57 & 2 & 16.2 & 125.5 & & \\
\hline & Son Çocuk & 61 & 2 & 15.5 & 113.4 & & \\
\hline \multirow{3}{*}{ Toplam Puan } & İlk Çocuk & 127 & 2 & 47.3 & 121.2 & \multirow{3}{*}{0.521} & \multirow{3}{*}{.771} \\
\hline & Ortanca & 57 & 2 & 49.4 & 128.9 & & \\
\hline & Son Çocuk & 61 & 2 & 47.8 & 121.2 & & \\
\hline
\end{tabular}

$* \mathrm{p}<.05$

Tablo 2 incelendiğinde, babaların çocuklarının doğum sırasına göre ÇocukAnababa İlişki Ölçeği'nin Çatışma Boyutu Alt Ölçeği $\left(X^{2}=0.491, p>.05\right)$, Olumlu İlişki Boyutu Alt Ölçeği $\left(X^{2}=1.51, p>.05\right)$ puanları ve toplam puanları $\left(X^{2}=0.521, p>.05\right)$ arasında istatistiksel olarak anlamlı bir fark bulunmamıştır. Bu sonuca göre, babaların çocukları ile olan ilişkilerinde doğum sırası değişkeninin etkili olmadığı söylenebilir. 
Tablo 3

Babaların Çocuklarının Sayısına Göre Çocuk-Anababa İlişki Ölçeği Puanlarına Iliş̧kin Kruskall-Wallis H Testi Sonuçları

\begin{tabular}{|c|c|c|c|c|c|c|c|c|}
\hline \multirow[b]{2}{*}{$C ̧ A \dot{I} O ̈$} & \multirow[b]{2}{*}{ Çocuk Sayısı } & \multicolumn{6}{|c|}{ Kruskal Wallis H Testi } & \multirow{2}{*}{$\begin{array}{c}\text { İkili } \\
\text { Karşılaştırma }\end{array}$} \\
\hline & & $n$ & $S d$ & $\bar{x}$ & $\begin{array}{l}\text { Sira } \\
\text { Ort. }\end{array}$ & $X^{2}$ & $p$ & \\
\hline \multirow{3}{*}{ Çatışma Boyutu } & Tek çocuk & 43 & 2 & 34.4 & 146.2 & \multirow{3}{*}{7.6} & \multirow{3}{*}{$.022 *$} & \multirow{3}{*}{$\begin{array}{l}2-3 \\
2-1\end{array}$} \\
\hline & İki çocuk & 135 & 2 & 30.6 & 113.1 & & & \\
\hline & $\begin{array}{c}\text { Üç ve daha fazla } \\
\text { çocuk }\end{array}$ & 67 & 2 & 33.1 & 128.1 & & & \\
\hline \multirow{3}{*}{$\begin{array}{l}\text { Olumlu İlişki } \\
\text { Boyutu }\end{array}$} & Tek çocuk & 43 & 2 & 15.8 & 120.4 & \multirow{3}{*}{0.237} & \multirow{3}{*}{.887} & \\
\hline & İki çocuk & 135 & 2 & 16.0 & 125.0 & & & \\
\hline & $\begin{array}{c}\text { Üç ve daha fazla } \\
\text { çocuk }\end{array}$ & 67 & 2 & 16.1 & 120.7 & & & \\
\hline \multirow{3}{*}{ Toplam Puan } & Tek çocuk & 43 & 2 & 50.2 & 140.6 & \multirow{3}{*}{5.0} & \multirow{3}{*}{.081} & \\
\hline & İki çocuk & 135 & 2 & 46.6 & 114.6 & & & \\
\hline & $\begin{array}{c}\text { Uç ve daha fazla } \\
\text { çocuk }\end{array}$ & 67 & 2 & 49.2 & 128.7 & & & \\
\hline
\end{tabular}

$* \mathrm{p}<.05$

Tablo 3 incelendiğinde, babaların çocuk sayısına göre Çocuk-Anababa İlişki Ölçeği'nin Çatışma Boyutu Alt Ölçeği $\left(X^{2}=7.6, p<.05\right)$ puanları arasındaki fark istatistiksel olarak anlamlı bulunurken, Olumlu İlişki Boyutu Alt Ölçeği $\left(X^{2}=0.237\right.$, $\mathrm{p}>.05)$ puanları ve toplam puanları $\left(\mathrm{X}^{2}=5, \mathrm{p}>.05\right)$ arasında ise fark istatistiksel olarak anlamlı bulunmamıştır. Çatışma boyutu puanının iki çocuklu ailelerde; tek çocuklu ve üç ve daha fazla çocuklu ailelere göre anlamlı derecede düşük olduğu görülmektedir. $\mathrm{Bu}$ sonuca göre, babaların çocukları ile olan ilişkilerinde çocuk sayısı değişkeninin çatışma boyutunda etkili olduğu söylenebilir.

Tablo 4

Babaların Öğrenim Durumlarına Göre Çocuk-Anababa İlişki Ölçeği Puanlarına İlişkin Kruskall-Wallis H Testi Sonuçlart

\begin{tabular}{|c|c|c|c|c|c|c|c|}
\hline \multirow[b]{2}{*}{ ÇAÏÖ } & \multirow{2}{*}{$\begin{array}{l}\text { Öğrenim } \\
\text { Durumu }\end{array}$} & \multicolumn{6}{|c|}{ Kruskal Wallis H Testi } \\
\hline & & $n$ & $S d$ & $\bar{X}$ & Stra Ort. & $X^{2}$ & $p$ \\
\hline \multirow{3}{*}{ Çatışma Boyutu } & İlköğretim & 123 & 2 & 32.8 & 129.2 & \multirow{3}{*}{2.69} & \multirow{3}{*}{.265} \\
\hline & Lise & 84 & 2 & 31.9 & 120.6 & & \\
\hline & Üniversite & 38 & 2 & 29.2 & 108.4 & & \\
\hline \multirow{3}{*}{ Olumlu İlişki Boyutu } & İlköğretim & 123 & 2 & 16.0 & 122.6 & \multirow{3}{*}{0.015} & \multirow{3}{*}{.992} \\
\hline & Lise & 84 & 2 & 15.8 & 123.0 & & \\
\hline & Üniversite & 38 & 2 & 16.0 & 124.2 & & \\
\hline \multirow{3}{*}{ Toplam Puan } & İlköğretim & 123 & 2 & 48.8 & 128.3 & \multirow{3}{*}{2.1} & \multirow{3}{*}{.338} \\
\hline & Lise & 84 & 2 & 47.8 & 121.6 & & \\
\hline & Üniversite & 38 & 2 & 45.3 & 109.1 & & \\
\hline
\end{tabular}

$* \mathrm{p}<.05$

Tablo 4 incelendiğinde, babaların öğrenim durumlarına göre Çocuk-Anababa İlişki Ölçeği'nin Çatışma Boyutu Alt Ölçeği $\left(X^{2}=2.69, p>.05\right)$, Olumlu İlişki Boyutu Alt Ölçeği $\left(\mathrm{X}^{2}=0.015, \mathrm{p}>.05\right)$ puanları ve toplam puanları $\left(\mathrm{X}^{2}=2.1, \mathrm{p}>.05\right)$ arasında fark 
istatistiksel olarak anlamlı bulunmamıştır. Bu sonuca göre, babaların çocukları ile olan ilişkilerinde öğrenim durumu değişkeninin istatistiksel açıdan etkili olmadı̆̆ görülmekle birlikte Çocuk-Anababa İlişki Ölçeği toplam puanına göre sıra ortalamaları dikkate alındığında; üniversite mezunu babaların ilköğretim ve lise mezunu babalara göre çocukları ile daha olumlu ilişkiye sahip olduğu söylenebilir.

\section{Sonuç ve Tartışma}

Çocuğu okul öncesi eğitim kurumuna devam eden alt sosyoekonomik düzeydeki babaların çocukları ile olan ilişkisinin bazı demografik değişkenlere (çocukların cinsiyeti, doğum sırası, evdeki çocuk sayısı, babanın öğrenim durumu) göre incelenmesi amacıyla yapılan araştırmada; babaların çocuklarının cinsiyetine göre Çocuk-Anababa İlişki Ölçeği'nin Çatışma Boyutu Alt Ölçeği puanları ve toplam puanları arasında istatistiksel olarak anlamlı derecede farklılık görülmezken, Olumlu İlişki Boyutu Alt Ölçeği puanları arasında istatistiksel olarak anlamlı derecede farklılık görülmektedir. Doğumdan itibaren anne-babalar cinsiyetine göre, bebeklerine karşı farklı davranışlar sergilemekte, çoğunlukla kendi cinsiyetindeki bebeklerine, karş1 cinsiyetteki bebeklerine oranla daha canlı bir şekilde şark1 söylemekte, fiziksel ve göz temasında bulunmaktadır. Ayrıca cinsiyete göre anne-babaların çocuklarından beklentileri de değişim göstermektedir (Bee \& Boyd, 2009). Alan yazında baba-çocuk ilişkisi incelendiğinde, çoğunlukla babaların kız ve erkek çocukları ile farklı şekillerde etkileşim kurma eğiliminde oldukları görülmektedir (Sımsıkı ve Şendil, 2014). Harris \& Morgan'ın (1991) baba-çocuk ilişkisi ve Hair ve diğerleri (2003) ebeveyn-çocuk ilişkisi ile ilgili araştırmalarında; babaların kız çocuklarına oranla erkek çocukları ile daha yakın ilişki kurdukları belirlenmiştir. Poyraz (2007) tarafından yapılan babaların babalık rolünü algılamaları ile ilgili araştırmada da babaların erkek çocukları ile kız çocuklarına oranla daha çok ilgilendikleri ve erkek çocukları ile daha çok zaman geçirdikleri sonucu ortaya çıkmıştır. Bununla birlikte, Ünüvar (2008) tarafından babaların çocukları ile geçirdikleri zamanın niteliğini belirme amacıyla yapılan araştırmada, bilişsel ve sosyal gereksinimler boyutunda kız çocuk sahibi babaların erkek çocuk sahibi babalara oranla çocukları ile geçirdikleri zamanın niteliğinin daha iyi düzeyde olduğu tespit edilmiş̧tir. Driscoll \& Pianta (2011) tarafından babaların okul öncesi dönemdeki çocuklarıyla ilişskilerinin incelendiği araştırmada da babaların erkeklere oranla kız çocukları ile daha yakın ilişki içerisinde oldukları sonucu ortaya çıkmıştır. Araştırma sonuçları incelendiğinde; değişen toplumsal rollerin ve çocuğun gelişiminde babanın önemine ilişkin bilgi artışının, babaların kız ve erkek çocukları ile olan etkileşimlerini etkilediği düşünülebilir. $\mathrm{Bu}$ bulgular doğrultusunda, babaların kız çocukları ile ilişkisinin erkek çocuklara göre daha olumlu olduğu yönündeki araştırma bulgusunun, alan yazındaki bazı araştırma sonuçlarıyla çeliştiği, bazı araştırma sonuçlarıyla ise paralellik gösterdiği söylenebilir.

Babaların çocuklarının doğum sırasına göre Çocuk-Anababa İlişki Ölçeği'nin Çatışma Boyutu Alt Ölçeği, Olumlu İlişki Boyutu Alt Ölçeği puanları ve toplam puanları arasında istatistiksel olarak anlamlı bir fark bulunmamıştır. Doğum sırası, anne-baba ile çocuk ilişkisi ve anne-baba tutumlarını etkileyebilmektedir (Bee \& Boyd, 
2009). Doğum sırasının anne-baba ile çocuk ilişkisine etkisi incelendiğinde; anne babaların ilk doğan çocuklarından beklentilerinin daha yüksek olduğu, ilk doğan çocukların davranışlarına daha fazla müdahale ettikleri, ilk çocuklardan daha olgun olmalarını bekledikleri, ilk çocuklarına karşı daha duyarlı davrandıkları ya da çocuk yetiştirme konusundaki acemiliklerinden dolayı daha çok baskı ve fiziksel ceza uyguladıkları görülmektedir (Güneysu, 1982, Akt. Şimsek, 2006; Bee \& Boyd, 2009; Gustafson, 2010; Memet, 2010). Buna bağlı olarak doğum sırası değişkeninin ele alındığ 1 araştırmalarda farklı sonuçlar elde edildiği görülmektedir. Haktanır ve Baran (1998) tarafından yapılmış olan araştırmada, gençlerin anne-baba tutumlarını algılamalarında doğum sırası etkisinin var olduğu sonucuna ulaşılmıştır. Bununla beraber 5-6 yaş grubunda çocuğu olan ebeveynlerin çocuk yetiştirme tutumlarının incelendiği bir araştırmada, anne baba tutumlarının çocuğun doğum sırasından bağımsız olduğu sonucuna ulaşılmıştır (Tezel Şahin ve Özyürek, 2008). Arabacı (2011) tarafından anne-baba-çocuk iletişiminin bazı değişkenler açısından değerlendirildiği araştırmada da çocukların doğum sırasına göre; konuşma, dinleme, sözsüz iletişim ve empati alt boyutlarında babaları ile iletişimlerinde anlamlı bir farklılık tespit edilmemiştir. Anne babaların okul öncesi dönemdeki çocukları ile ilişkisi konusundaki araştırmalarda doğum sırasına göre babanın çocuklarıyla ilişkilerinde anlamlı farklılı̆̆ın çıkmaması bulgusu, bu araştırma sonucu ile paralellik göstermektedir.

Babaların çocuk sayısına göre Çocuk-Anababa İlişki Ölçeği'nin Çatışma Boyutu Alt Ölçeği puanları arasındaki fark istatistiksel olarak anlamlı bulunurken, Olumlu İlişki Boyutu Alt Ölçeği puanları ve toplam puanları arasında ise fark istatistiksel olarak anlamlı bulunmamıştır. Çatışma boyutu puanının iki çocuklu ailelerde; tek çocuklu ve üç ve daha fazla çocuklu ailelere göre anlamlı derecede düşük olduğu görülmektedir. Ailedeki çocuk sayısının artması, anne babanın her bir çocukla geçireceği zamanın azalmasına ve çocuklara gösterilen ilgi ve sevginin bölünmesine yol açmaktadır (Şimşek, 2006; Memet, 2010). Margolis \& Myrskyla (2010) yaptıkları çalışmada, annebabaların çocuk sayısı arttıkça, mutsuzluk düzeyinin arttığını tespit etmişlerdir. Annebabanın mutsuzluğu, çocukları ile olan ilişkilerini de olumsuz yönde etkilemektedir. Poyraz'ın (2007) babaların babalık rolünü algılamaları ile ilgili araştırmasında, sahip olunan çocuk sayısı arttıkça babanın, babalık algısının da olumsuz yönde değiştiği; Seçer, Çeliköz ve Yaşa'nın (2007) bazı kişisel özelliklerine göre okul öncesi eğitim kurumlarına devam eden çocukların babalarının babalığa yönelik tutumlarını inceledikleri araştırmalarında, babaların iki çocuktan sonra babalığa yönelik ilgisinin azalmaya başladığı tespit edilmiştir. Arabacı'nın (2011) anne-baba-çocuk iletişimi ile ilgili araştırmasında, mesaj alt boyutunda anne baba puanlarının çocuk sayısının artışına bağlı olarak azaldığı belirlenmiştir. Yukarıda verilen araştırma sonuçları, yapılan çalışmada ortaya konulan, babaların çok sayıda çocuğa sahip olma durumunun çocukları ile ilişkilerini olumsuz yönde etkilediği sonucu ile paralellik göstermektedir. Veenhoven \& Verkuyten (1989), tek çocuğa sahip olan ailelerin daha müdahaleci ve koruyucu bir tutum sergilemesi nedeniyle tek çocukların daha yalnız olduklarını ve sosyal becerilerini geliştirebilecek firsatlardan noksan olduklarını öne sürmüşlerdir (Akt: Avşar, 2013). Brody (1998) ise kardeş sayısına bağlı olarak evde çatışmaların 
artmasına rağmen, bu çatışmaların, çocukların iletişim yeteneklerinin gelişmesine ve duygularını iletebilmesine yarar sağlaması sonucunda diğer ilişkilerinde de uzlaşmaya varabilmeleri için alıştırma yapmalarına olanak sağlayacağını düşünmektedir fakat tek çocuklu olanların bu gereksinimlerini aile üyeleri ve başka akranlarıyla giderebileceklerini belirtmektedir. Bu durumun, tek çocuğa sahip olan babaların çatışma boyutu alt ölçeği puanlarının iki çocuğa sahip olan babalara göre daha yüksek olmasını etkilediği düşünülmektedir.

Babaların öğrenim durumlarına göre Çocuk-Anababa İlişki Ölçeği'nin Çatışma Boyutu Alt Ölçeği, Olumlu İlişki Boyutu Alt Ölçeği puanları ve toplam puanları arasında fark istatistiksel olarak anlamlı bulunmamıştır. Bu sonuca göre, babaların çocukları ile olan ilişkilerinde öğrenim durumu değişkeninin istatistiksel açıdan etkili olmadığı görülmekle birlikte Çocuk-Anababa İlişki Ölçeği toplam puanına göre sira ortalamaları dikkate alındığında; üniversite mezunu babaların ilköğretim ve lise mezunu babalara göre çocukları ile daha olumlu ilişkiye sahip olduğu söylenebilir. Babaların çocukları ile oynaması, konuşması, onları dinlemesi, beslenme temizlik gibi temel gereksinimlerini karşılaması baba-çocuk arasında kurulan ilişkinin temelini oluşturmaktadır (Amato, 1994; Thomas, Krampe \& Newton, 2008). Baba-çocuk arasında gelişen olumlu ilişki babanın çocuk yetiştirme tutumu üzerinde de etkili olmakta ve babanın çocuk yetiştirmede daha demokratik bir tutum sergilemesini sağlamaktadır (Bee \& Boyd, 2009; Berk, 2013). Ayrıca eğitim düzeyi yükseldikçe daha demokratik ve esnek bir cinsiyet rolüne sahip olan baba, çocuk gelişimi konusunda kendisini daha yeterli gördüğü için ebeveyn sorumluluğunu alarak çocuk bakımına daha aktif olarak katılmaktadır (Poyraz, 2007; Kuzucu, 2011). Er Gazeloğlu (2000)'in annebaba tutumunun ilkokul dördüncü sınıf öğrencilerinin psiko-sosyal gelişimine etkisini değerlendirdiği; Özyürek ve Tezel Şahin (2005)'in 5-6 yaş çocuklarının anne-baba tutumlarını değerlendirdiği ve Gürşimşek (2008)'in ise anne-babaların çocuk yetiştirme ve eğitimine ilişkin inanç ve değerlerini incelediği araştırmalarında, eğitim seviyesi yükseldikçe ebeveynlerin geleneksel çocuk yetiştirme tutumlarının azaldığ1 belirlenmiştir. Dizman (2003) tarafından anne-babası ile yaşayan ve anne yoksunu olan çocukların saldırganlık eğilimlerinin incelenmesi amacıyla yapılan araştırmada, eğitim düzeyi artıkça babaların geleneksel tutumdan uzak bir şekilde çocuğunu yetiştirdiği ve çocuğuyla paylaşımlarının da arttığ 1 tespit edilmiştir. Criss ve diğerleri (2002) tarafından ailedeki pozitif ilişkinin çocukların davranışları üzerindeki etkisinin incelendiği araştırmada, eğitim düzeyi arttıkça anne-babanın çocukları ile ilişkilerinin daha arkadaşça olduğu ve çocukların babalarını daha demokratik buldukları sonucu ortaya çıkmıştır. Seçer, Çeliköz ve Yaşa'nın (2007) araştırmalarında ise, babaların eğitim düzeyi arttıkça kendilerini babalık işinde daha yeterli gördükleri ve üniversite mezunu babaların ilköğretim mezunu babalara göre babalığa yönelik ilgisinin ve genel tutumunun daha olumlu olduğu tespit edilmiştir. Ünüvar (2008) tarafından babaların çocukları ile geçirdikleri zamanın niteliğini belirme amacıyla yapılan araştırmada da eğitim düzeyi düşük olan babaların, çocukları ile zaman geçirmeyi anneye ait bir etkinlik olarak görme eğiliminde oldukları belirlenmiştir. $\mathrm{Bu}$ araştırma sonucunda babanın eğitim seviyesi ile çocuk-baba ilişkisi arasında istatistiksel olarak anlamlı bir 
farklılık olmamasına rağmen, eğitim seviyesi yükseldikçe babanın çocukları ile daha olumlu ilişki kurması, alan yazındaki baba eğitim durumunun çocuk yetiştirme tutumu ve baba-çocuk ilişkisine etkisi ile ilgili çalışmaların bulguları ile benzerlik göstermektedir.

\section{Öneriler}

Baba-çocuk ilişkisinde, cinsiyet, çocuk sayısı, babanın öğrenim durumu gibi değişkenlerin önemli olduğu göz önüne alındığında; etkili iletişim, anne baba tutumları, olumlu davranış geliştirme gibi konularda eğitim programları hazırlanarak, alt sosyoekonomik düzeyde baba katılımlı aile eğitimleri yapılabilir.

Babaların çocukların yaşamında ne kadar etkili olduğuna ilişkin tüm toplumun bilinçlendirilmesi amacıyla, afişler, broşürler, ilanlar, kitapçıklar ve televizyon reklamları hazırlanarak, medya ve basın yayın ile iş birliği içerisinde babalara eğitim desteği sağlanabilir.

Okul öncesi eğitim kurumlarında ve halk eğitim merkezlerinde baba-çocuk ilişkisini güçlendirecek, baba ve çocuğun birlikte nitelikli zaman geçirmesini sağlayacak projeler geliştirilerek baba destek programları yaygınlaştırılabilir. 


\section{Kaynakça}

Akgün, E. \& Yeşilyaprak, B. (2010). Çocuk Anababa İlişki Ölçeği Türkçe formunun geçerlik ve güvenirlik çalışması. Balıkesir Üniversitesi Sosyal Bilimler Enstitüsü Dergisi, 13(24), 44-53.

Amato, P.R. (1994). Father-child relations, mother-child relations, and offspring psychological well-being in early adulthood. Journal of Marriage and Family, 56(4), 1031-1042.

Arabacı, N. (2011). Anne-baba-çocuk iletişimini değerlendirme aracının (ABÇİDA) geliştirilmesi ve anne-baba-çocuk iletişiminin bazı değişkenler açısından incelenmesi (Yayımlanmamış Doktora Tezi). Gazi Üniversitesi Eğitim Bilimleri Enstitüsü, Ankara.

Avşar, A.H. (2013). Ergen bireylerde sosyal beceri düzeyinin kardeşli ve tek çocuklu olma açısından incelenmesi (Yayımlanmamış Yüksek Lisans Tezi). İstanbul Arel Üniversitesi Sosyal Bilimler Enstitüsü, İstanbul.

Barber, B.K. \& Erickson, L.D. (2001). Adolescent social initiative: Antecedents in the ecology of social connections. Journal of Adolescent Research, 16(4), 326-354.

Bee, H. \& Boyd, D. (2009). Çocuk gelişim psikoloji (Çev: Okhan Gündüz). İstanbul: Kaknüs Yayınları. Eserin Orjinali: The developing Child, 2007.

Berk, L. (2013). Çocuk gelişimi (Çev: Ali Dönmez). Ankara: İmge Yayıncılık. Eserin Orjinali: Child Development, 2009.

Brody, G.H. (1998). Sibling relationship quality: Its causes and consequences. Annual Review of Psychology, 49, 1-24. DOI: 10.1146/annurev.psych.49.1.1.

Browne, C.S. \& Rife, J.C. (1991). Social, personality, and gender differences in at-risk and not at risk sixth-grade students. Journal of Early Adolescence, 11, 482-495.

Büyüköztürk, Ş., K1lıç, E., Akgün, Ö.E., Kardeniz, Ş. \& Demirel, F. (2009). Sosyal bilimlerde araştırma teknikleri. Ankara: Pegem Akademi Yayıncılık.

Coley, R.L. \& Morris, J.E. (2002). Comparing father and mother reports of father involvement among low-income minority families. Journal of Marriage and Family, 64(4), 982-997.

Criss, M.M, Petit, G.S., Bates, J.E., Dodge, K.A. \& Lapp, A.L. (2002). Family adversity, positive peer relationship and children's externalizing behaviour: A longitudinal perspective on risk and resilience. Child Development, 73(4), 12201237.

Dizman, H. (2003). Anne babası ile yaşayan ve anne yoksunu olan çocukların saldırganlık ĕgilimlerinin incelenmesi (Yayımlanmamış Yüksek Lisans Tezi). Ankara Üniversitesi Fen Bilimleri Enstitüsü, Ankara.

Driscoll, K. \& Pianta, R.C. (2011). Mothers' and fathers' perceptions of conflict and closeness in parent-child relationships during early childhood. Journal of Early Childhood and Infant Psychology, 7, 1-24. 
Er Gazeloğlu, C. (2000). İlkokul dördüncü sınıf öğrencilerinin psiko-sosyal gelişimine ana-baba tutumunun etkisinin incelenmesi (Yayınlanmamış Yüksek Lisans Tezi). Hacettepe Üniversitesi Sağlık Bilimleri Enstitüsü, Ankara.

Grossmann, K., Grossmann, K.E., Frember-Bombik, E., Kindler, H., ScheuererEnglisch, H. \& Zimmermann, P. (2002). The uniqueness of the child-father attachment relationship: Fathers' sensitive and challenging play as a pivotal variable in a 16 year longitudinal study. Social Development, 11(3), 307-331.

Gustafson, C. (2010). The effects of birth order on personality. (Unpublished Master Thesis). The Faculty of the Alfred Adler Graduate School, Minneapolis, ABD.

Gürşimşek, I. (2008). Anne babaların çocuk yetiştirme ve eğitimine ilişkin inanç ve değerleri. Proceedings of International Conference of Educational Sciences (ICES'08), (ss. 916-925), Özer, B., Yaratan, H., Caner, H. (Ed.), 23-25 Haziran 2008 Yakındoğu Üniversitesi Famagusta, TRNC

Hair, E.C., Moore, K.A., Garret, S.B., Kinukawa, A., Lippman, L. \& Michelsen, E. (2003). Psychometric analyses of the parent-adolescent relationship scale in the national longitudinal survey of youth-1997. Indicators of Positive Development Conference, 1-31, 12-13 March 2003, Washington, DC. Erişi Tarihi: 20.08.2014. Web adresi: http://www.childtrends.org

Haktanır, G. \& Baran, G. (1998). Gençlerin benlik saygısı düzeyleri ile anne baba tutumlarını algılamalarının incelenmesi. Çocuk ve Ergen Ruh Sağlığı Dergisi, 5(3), 134-141.

Hamamcı, Z. (2005). Üç-altı yaşlarında çocukları olan anne ve babaların aile eğitim ihtiyaçlarının belirlenmesi. Çă̆daş Eğitim Dergisi, 30, (319). Erişi Tarihi: 20.08.2014. Web adresi:http://www.cagdasegitim.org/?set=aylik\&arsiv=200504.

Harris, K.M. \& Morgan, S.P. (1991). Fathers, sons and doughters: differential paternal, involvement in parenting. Journal of Marriage and the Familly, 53(3), 531-544.

Ishii-Kuntz, M., Makino, K., Kato, K. \& Tsuchiya, M. (2004). Japanese fathers of preschoolers and their involvement in child care. Journal of Marriage and Family, 66(3), 779-791. DOI: 10.1111/j.0022-2445.2004.00052.x

Koç, A. (2000). Ergenlerin sosyal uyumunu inceleyen bazı değişkenlerin incelenmesi. (Yayımlanmamış Yüksek Lisans Tezi). Atatürk Üniversitesi Sosyal Bilimler Enstitüsü, Erzurum.

Kuzucu, Y. (2011). Değişen babalık rolü ve çocuk gelişimine etkisi. Türk Psikolojik Danışma ve Rehberlik Dergisi, 4(35), 79-89.

Lamb, M.E. (2010). How the fathers influence children's development. Let me count the ways. In M. E. Lamb (Eds), The role of father in child development (5rd Ed.) (pp.1-26). New York: John Wiley.

Margolis, R. \& Myrskylä, M. (2010). A global perspective on happiness and fertility. Population and Development Review 37(1), 29-56. DOI: 10.1111/j.17284457.2011.00389.x 
Marsiglio, W., Amato, P.R, Day, R. \& Lamb, M.E. (2000). Scholarship on fatherhood in the 1990s and beyond. Journal of Marriage and the Family, 62(4), 11731191.

McBride, B.A., Schoppe, S.J. \& Rane, T. R. (2002). Child characteristics, parenting stress, and parental involvement: Fathers versus mothers. Journal of Marriage and Family, 64(4), 998-1011. DOI: 10.1111/j.1741-3737.2002.00998.x

Memet, N. (2010). Ebeveynlerin çocuklarına ilişkin sosyalleştirme hedeflerinin, kültürel değer yönelimleri ve ĕgitim düzeyleri ile çocuğun cinsiyeti ve doğum sırası açılarından incelenmesi (Yayınlanmamış Yüksek Lisans Tezi). İstanbul Üniversitesi Sosyal Bilimler Enstitüsü, İstanbul.

Özyürek, A. \& Tezel Şahin, F. (2005). 5-6 yaş grubunda çocuğu olan ebeveynlerin tutumlarının incelenmesi. Gazi Üniversitesi Gazi Eğitim Fakültesi Dergisi, 25(2), 19-34.

Paquette, D., Bolté, C., \& Dubeau, D., Bouchard, C. (2000). A new typology of fathering: Defining and associated variables. Infant and Child Development, 9(4), 213-230. DOI: $\quad$ 10.1002/1522-7219(200012)9:4<213:AIDICD233>3.0.CO;2-0

Paquette, D., Carbonneau, R., Dubeau, D., Bigras, M. \& Tremblay, R.E. (2003). Prevalence of father-child rough-and-tumble play and physical aggression in preschool children. European Journal of Psychology of Education, 18(2), 171189.

Paulson, J. F., Dauber, S.E., \& Leiferman, J.A. (2010). Parental depression, relationship quality, and nonresident father involvement with their infants. Journal of Family Issues, 32(4), 528-549. doi:10.1177/0192513X10388733.

Pianta, R.C. (1997). Adult-child relationship processes and early schooling. Early Education and Development, 8(1), 11-26.

Pianta, R.C. (1999). Enhanching relationship between children and teachers. Washington DC: American Psychological Association.

Poyraz, M. (2007). Babaların babalık rolünü algllamalarıla kendi ebeveynlerinin tutumları arasındaki ilişkinin incelenmesi (Yayımlanmamış Yüksek Lisans Tezi). Gazi Üniversitesi Eğitim Bilimleri Enstitüsü, Ankara.

Seçer, Z., Çeliköz, N. \& Yaşa, S. (2007). Bazı kişisel özelliklerine göre okul öncesi eğitim kurumlarına devam eden çocukların babalarının babalığa yönelik tutumları. Selçuk Üniversitesi Sosyal Bilimler Enstitüsü Dergisi, 18, 425-438.

Sezer, Ö. (2010). Ebeveynlerin kendilik algılarının anne baba tutumları ve bazı değişkenler açısından incelenmesi. Yüzüncü Yıl Üniversitesi Eğitim Fakültesi Dergisi, 7(1), 1-19.

Sımsıkı, H. \& Şendil, G. (2014). Baba katılım ölçeği'nin (BAKÖ) geliştirilmesi. Elektronik Sosyal Bilimler Dergisi, 13(49), 104-123. 
Şimsek, A. (2006). Duygusal zekanın, ana-baba tutumunun ve doğum sırasının tercih edilen liderlik tarzına etkisi (Yayınlanmamış Yüksek Lisans Tezi). Ankara Üniversitesi Sosyal Bilimler Enstitüsü, Ankara.

Taris, T.W. \& Bok, I.A. (1996). Parenting environment and scholastic achievement during adolescence: A retrospective study. International Journal of Adolescence and Youth, 6(3), 223-244.

Tezel Şahin, F. (2003). Çocuğun gelişimi ve eğitiminde babanın rolü. In M. Sevinç (Ed.), Erken Çocuklukta Gelişim ve Eğitimde Yeni Yaklaşımlar (pp. 459-463). İstanbul: Morpa Kültür Yayınları.

Tezel Şahin, F. \& Özyürek, A. (2008). 5-6 yaş grubunda çocuğu sahip ebeveynlerin demografik özelliklerinin çocuk yetiştirme tutumlarına etkisinin incelenmesi. Türk Ĕ̈itim Bilimleri Dergisi, 6(3) 395-414.

Thomas, P.A., Krampe, E.M. \& Newton, R.R. (2008). Father presence, family structure, and feelings of closeness to the father among adult African American Children. Journal of Black Studies, 38(4), 529-546.

Ünüvar, P. (2008). Babaların 3-6 yaş grubu çocuklarlyla geçirdikleri zamanın niteliğini belirleme ve geliştirme (Yayınlanmamış Doktora Tezi). Selçuk Üniversitesi Sosyal Bilimler Enstitüsü, Konya.

Wood, J.J. (2007). Academic competence in preschool: Exploring the role of close relationship and anxiety. Early Education and Development, 18(2), 223-242. 